The International Journal of Indian Psychology

ISSN 2348-5396 (e) | ISSN: 2349-3429 (p)

Volume 5, Issue 1, DIP: 18.01.064/20170501

DOI: $10.25215 / 0501.064$

http://www.ijip.in | October-December, 2017

Research Article

\title{
A Comparative Study of the Relationship of Attitude towards \\ Dress and Self-Concept between Female and Male Students of College
}

\author{
Harshita Ahuja ${ }^{1 *}$
}

\section{ABSTRACT}

The objective of this study is to study the relationship between attitude towards dress (as a function of self expression, interpersonal attraction, identity and self, body image, emotions, social, aesthetics, success and personality) and self-concept. A sample of 80 college going 40 males and 40 females, was chosen using the method of purposive sampling. The results were subject to statistical analysis like descriptive statistics and correlation, show that both girls and boys have equally favourable attitude towards dress but differ significantly on Self Concept. Also relationship between attitude towards dress and self concept is seen to some extent. In girls Aesthetic Self concept relates negatively to attitude towards dress whereas in boys Aesthetic self concept relates positively to Attitude towards dress. Also there is a positive relationship between Character self concept and Attitude towards dress in females but no relation among the same in boys. A negative relationship on emotional self concept and Attitude towards dress is exhibited in boys unlike girls who show no relationship. Also Intellectual Self concept is not related to Attitude towards dress in both. A comprehensive understanding of how these variables are related and underlying gender differences can be vital influence on youth's sense of self, growth and wellbeing.

Keywords: Attitude, Dress, Self-Concept

There's no way I set out to be a certain kind of symbol - the way I dress is the way I am, the way I live my life. - Pamela Anderson

What's the secret to being confident? Some people believe it's having a positive mental attitude, while others claim it's being wealthy.

But according to one researcher, the answer may in fact lie in what we're wearing.

Dress is defined as "an assemblage of modifications of the body and/or supplements to the body" Putting on different clothes creates different thoughts and mental processes.

\footnotetext{
${ }^{1}$ Assistant Professor, Patrician College for Women, Dehradun, India *Responding Author

Received: August 15, 2017; Revision Received: November 25, 2017; Accepted: December 05, 2017 (C) 2017 Ahuja H; licensee IJIP. This is an Open Access Research distributed under the terms of the Creative Commons Attribution License (www.creativecommons.org/licenses/by/2.0), which permits unrestricted use, distribution, and reproduction in any Medium, provided the original work is properly cited
} 


\section{A Comparative Study of the Relationship of Attitude towards Dress and Self-Concept between Female and Male Students of College}

One's self-concept (also called self-construction, self-identity, self-perspective or selfstructure) is a collection of beliefs about oneself that includes elements such as academic performance, gender roles, sexuality, and racial identity. Generally, self-concept embodies the answer to "Who am I?" One's self-concept is made up of self-schemas, and their past, present, and future selves.

Self-concept is distinguishable from self-awareness, which refers to the extent to which selfknowledge is defined, consistent, and currently applicable to one's attitudes and dispositions. Self-concept also differs from self-esteem: self-concept is a cognitive or descriptive component of one's self (e.g. "I am a fast runner"), while self-esteem is evaluative and opinionated (e.g. "I feel good about being a fast runner").

Self-concept is made up of one's self-schemas, and interacts with self-esteem, selfknowledge, and the social self to form the self as whole. It includes the past, present, and future selves, where future selves (or possible selves) represent individuals' ideas of what they might become, what they would like to become, or what they are afraid of becoming. Possible selves may function as incentives for certain behavior.

A person's ideal self may not be consistent with what actually happens in life and experiences of the person. Hence, a difference may exist between a person's ideal self and actual experience. This is called incongruence.

Where a person's ideal self and actual experience are consistent or very similar, a state of congruence exists. Rarely, if ever does a total state of congruence exist; all people experience a certain amount of incongruence. The development of congruence is dependent on unconditional positive regard. Roger's believed that for a person to achieve self-actualization they must be in a state of congruence.

The review of literature including the previous researches and studies in the field of psychology of dress and its relationship with self concept was undertaken by the researcher in gaining extensive knowledge. Information on internet proved to be a great help in providing the researcher with latest studies.

1. A study of clothing interest in relation to Personality and Mental Health has been done by Usha Kulshrestha and Radha Kashyap: Where 100 adolescent girls were administered Clothing Interest Scale (Gruel and Gruel, 1979), Indian adaptation of Neyman-Kohlestedt diagnostic test for introversion-extroversion, Mental Health Inventory. The study revealed a significant correlation of personality and mental health with clothing interest. It was found that girls who were extrovert and had good mental health had greater clothing interest.

2. Morse and Gergen (1970) showed that in uncertain or anxiety arousing situations our selfesteem may change rapidly. Participants were waiting for a job interview in a waiting room. 


\section{A Comparative Study of the Relationship of Attitude towards Dress and Self-Concept between Female and Male Students of College}

They were sat with another candidate (a confederate of the experimenter) in one of two conditions:

A) Mr. Clean - dressed in smart suit, carrying a briefcase opened to reveal a slide rule and books.

B) Mr. Dirty - dressed in an old T-shirt and jeans, slouched over a cheap sex novel.

Self-esteem of participants with Mr. Dirty increased whilst those with Mr. Clean decreased! No mention made of how this affected subjects' performance in interview. Level of self-esteem affects performance at numerous tasks though (Coopersmith, 1967) so could expect Mr. Dirty subjects to perform better than Mr. Clean.

(1982) -

3. In the 1980s, Kellerman and Laird (1982) utilized self-perception theory to see whether wearing a specific item of dress (e.g., eye glasses) would influence peoples' ratings of their own skills and abilities. They conducted an experiment with undergraduate students having them rate themselves on an array of traits when wearing and when not wearing glasses and to complete a hidden figures test. Although there were no significant differences in their performance on the test, the participants' ratings of their competence and intelligence was higher when wearing glasses than when not. In related research, Solomon and Schopler (1982) found that both men and women indicated that the appropriateness of their clothing affected their mood.

(1986) -

4. Edmonds and Cahoon (1986) and Cahoon and Edmonds (1987) found ratings of women who wore provocative dress were more negative than ratings of women who wore nonprovocative dress. No specific theory was identified by these authors as guiding their research. Overall, when wearing provocative dress a model was rated more sexually appealing, more attractive, less faithful in marriage, more likely to engage in sexual teasing, more likely to use sex for personal gain, more likely to be sexually experienced, and more likely to be raped than when wearing conservative dress. Cahoon and Edmonds found that men and women made similar judgments, although men's were more extreme than women's. (1987) -

5. Abbey et al. (1987) studied whether women's sexual intent and interest as conveyed by revealing dress was misinterpreted by men. The authors developed two dress conditions: revealing (slit skirt, low cut blouse, high heeled shoes) and non-revealing (skirt without a slit, blouse buttoned to neck, boots). Participants rated the stimulus person on a series of adjective traits. As compared to when wearing the non-revealing clothing, when wearing the revealing clothing the stimulus person was rated significantly more flirtatious, sexy, seductive, promiscuous, sophisticated, assertive, and less sincere and considerate. This research was not guided by theory.

(1988) -

6. Social psychologists Mark Frank and Thomas Gillovich (1988) found that male football players and male ice hockey players who wore black uniforms played more aggressively (as evidenced by the number of penalties awarded) than players wearing white jerseys. In a related study these researchers had participants wear either black jerseys or white ones and 


\section{A Comparative Study of the Relationship of Attitude towards Dress and Self-Concept between Female and Male Students of College}

asked participants to indicate the type of games they wanted to play. As compared to participants wearing white jerseys, those wearing black jerseys selected more aggressive games to play.

(1992) -

7.Dress researcher Sally Francis (1992) found in her research that believing that one does not own the appropriate items of dress or that chosen body modifications are somehow unacceptable to others can prevent individuals from participating in some events and interacting with others.

(1994) -

8. Studying dress specifically within a workplace context, in the 1990s Kwon (1994) did not have her participants actually wear different clothing styles but asked them to project how they might think about themselves if they were to wear appropriate versus inappropriate clothing to work. Participants indicated they would feel more competent and responsible if they wore appropriate rather than inappropriate clothing.

(1997) -

9. Similarly, Rafaeli et al. (1997) ${ }^{\mathrm{a}}$ found that employees indicated a link between selfperception and clothing associating psychological discomfort with wearing inappropriate dress for work and increased social self-confidence with appropriate attire.

(1998) -

10. In addition to research that documents how our dress impacts self-perceptions, dress has also been shown to exert an influence on one's own behavior. For example, a team of social psychologists Barbara Fredrickson, Tomi-Ann Roberts, Stephanie Noll, Diane Quinn, and Jean Twenge (1998) found that when women put on a swimsuit as part of a research project, they performed more poorly on a subsequent math test than other women who put on a sweater.

\section{METHOD}

\section{Problem}

To do a comparative study of the relationship between Attitude towards Dress (assemblage of modifications of the body and/or supplements to the body) and Self Concept between college (Professional) going male and female students.

\section{Sample}

The entire sample for the study was taken from Petroleum University, Dehradun. The research population consisted of students from various branches of management. The sample consists of 80 students. The age group of students ranged from 19-21 years (BBA III sem)

\section{Purposive sampling}

The present study was done using purposive technique. This sampling procedure is also known as judgemental sample as the investigator has some belief that the sample being picked up is typical of the population. 


\section{A Comparative Study of the Relationship of Attitude towards Dress and Self-Concept between}

Female and Male Students of College

\section{Hypotheses}

Ho1-There will be no significant difference between the mean scores of Attitude towards Dress of male and female students

Ho2- There will be no significant difference between the mean scores of Self Concept of male and female students

Ho3- There would be no significant correlation between Attitude towards Dress and Self Concept of male and female students

$>\quad \mathbf{H o 3}$ a) There will be no significant correlation between Attitude towards Dress and Aesthetic aspect of Self Concept

$>\quad$ Ho3 b) There will be no significant correlation between Attitude towards Dress and character aspect of Self Concept

$>\quad$ Ho3 c) There will be no significant correlation between Attitude towards Dress and social aspect of Self Concept

$>\quad H o 3$ d) There will be no significant correlation between Attitude towards Dress and emotional aspect of Self Concept

$>\quad$ Ho3 e) There will be no significant correlation between Attitude towards Dress and intellectual aspect of Self Concept

\section{Materials used}

Self made comprehensive questionnaire on Attitude towards Dress (ATD)

Self Concept Scale (old personality word list) SCS-DP

\section{Procedure}

Firstly a questionnaire on Attitude towards Dress was drafted followed by multiple amendments to its present form. It was then filled by 15 respondents (along with their feedbacks) and analysed before being finally applied to the sample. This gave the researcher some preliminary insight. The sample being decided the subjects were chosen and given the questionnaire on Attitude towards Dress (ATD) and the Self Concept Scale (SCS-DP) to fill. The procedure and instructions were same for all students. They were motivated to answer honestly.

\section{RESULTS}

TABLE 1. Showing the total mean scores obtained by female and male college students respectively on Attitude towards Dress (ATD)

\begin{tabular}{|l|l|l|}
\hline \multicolumn{1}{|c|}{ GENDER } & $\begin{array}{l}\text { NUMBER } \\
\text { STUDENTS }\end{array}$ & OF \\
\hline Female & 40 & 97.07 \\
\hline Male & 40 & 95.54 \\
\hline
\end{tabular}

\begin{tabular}{|l|l|}
\hline $\mathbf{t}=$ & .37 \\
\hline
\end{tabular}

(t - Returns the probability associated with the student's t- test)

(C) The International Journal of Indian Psychology, ISSN 2348-5396 (e) | ISSN: 2349-3429 (p) | 32 
Fig 1.Graph showing the comparison of mean attitude towards dress scores obtained by male and female college students.

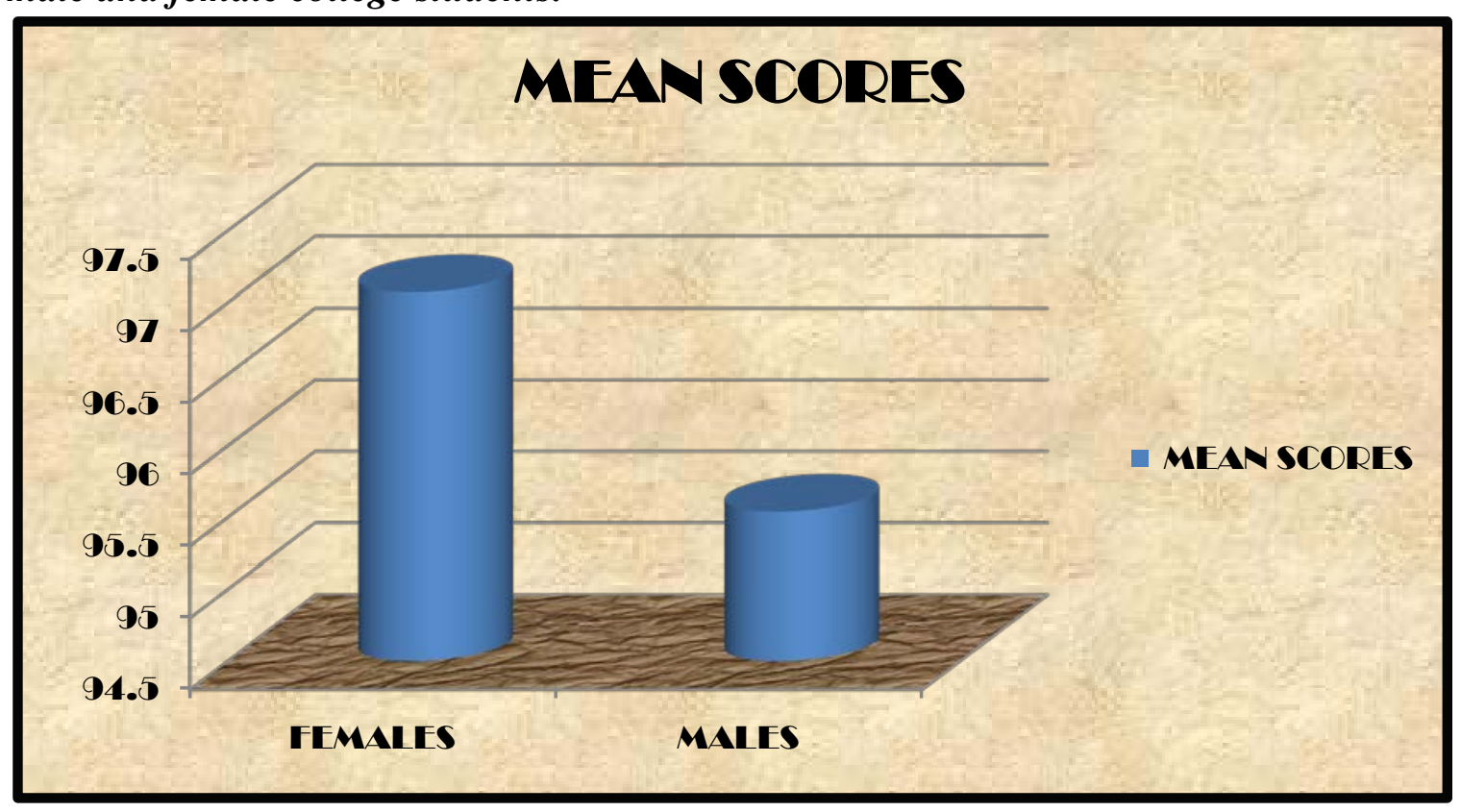

Table 1 and Fig. 1. shows the mean scores of Attitude towards Dress obtained by female and male students respectively. Here it is observed that the students of the two genders obtained mean score which a different from each other. The female students obtained 97.07 and Male students obtained 95.54, with a difference of 1.53 units between the two. The difference is small but it is clear that girls have slightly more favourable attitude towards dress than boys. As far as category is concerned both fall in "favourable attitude towards dress".

\section{SCORES DESCRIPTION}

0-26 Highly Unfavourable Attitude towards Dress

27-52 Unfavourable Attitude towards Dress

53-78 Moderate/ Neutral Attitude towards Dress

79-104 Favourable Attitude towards Dress

105-130 Highly Favourable Attitude towards Dress

TABLE 2. Showing the total mean scores obtained by female and male college students respectively on Self-Concept

\begin{tabular}{|l|l|l|l|}
\hline \multicolumn{1}{|l|}{ GENDER } & \multicolumn{2}{|l|}{ NUMBER OF STUDENTS } & MEAN SCORES \\
\hline FEMALE & 40 & 488.47 \\
\hline$M A L E \quad 40$ & & 465.46 \\
\hline \multicolumn{1}{|l|}{$\mathbf{t}=$} & $\mathbf{. 0 5}$ \\
\hline
\end{tabular}

( $\mathbf{t}$ - Returns the probability associated with the student's t- test) 
Fig 2.Graph showing the comparison of mean self concept scores obtained by male and female college students.

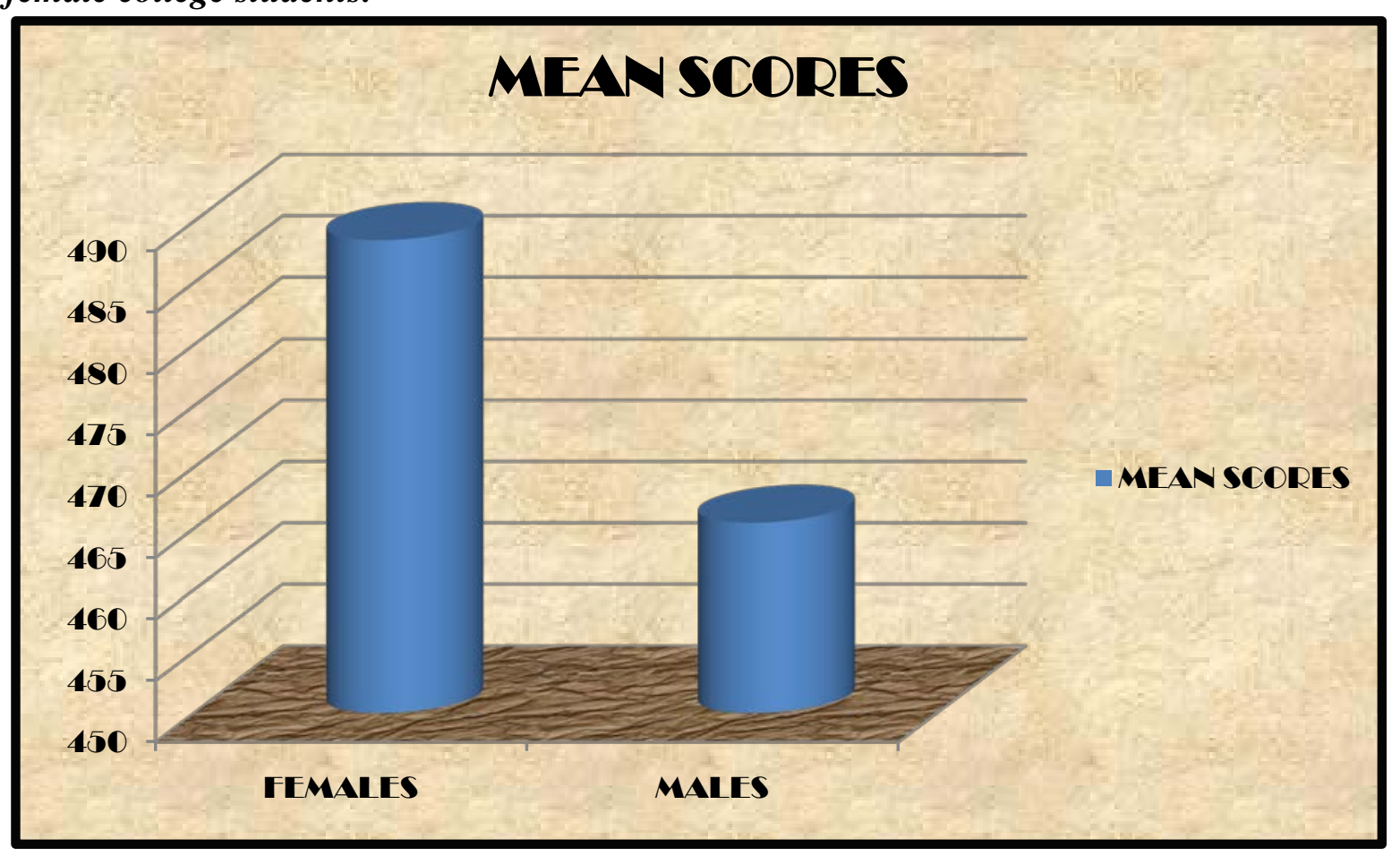

Table 2 and Fig 2 show the difference between mean self concept scores of female and male students respectively. Table2 and fig 2 demonstrates the difference between total self concept mean scores. The total self concept mean score of female students is 488.47 and of males is 465.46. A difference of 23.01. Therefore it is clear that girls have higher self concept than boys.

TABLE 3. Showing the mean scores obtained by female and male college students respectively on various aspects/characteristics of Self-Concept

\begin{tabular}{|l|l|l|}
\hline MEAN SCORES & FEMALES(N=40) & MALES(N=40) \\
\hline A)Aesthetic & 21.93 & 19.28 \\
\hline B)Character & 244.63 & 236.49 \\
\hline C)Social & 64.95 & 63.59 \\
\hline D)Emotional & 89.63 & 83.59 \\
\hline E)Intellectual & 68.95 & 62.23 \\
\hline
\end{tabular}

TABLE 5. Table showing correlation between Attitude Towards Dress And Total Self Concept Score.

\begin{tabular}{|l|l|}
\hline Gender & $\begin{array}{l}\text { Correlation Between Attitude Towards Dress And Self } \\
\text { Concept }\end{array}$ \\
\hline Females & .0938 \\
\hline Males & .0374 \\
\hline
\end{tabular}


FIG 5. Graph showing correlation between attitude towards dress and total self concept score.

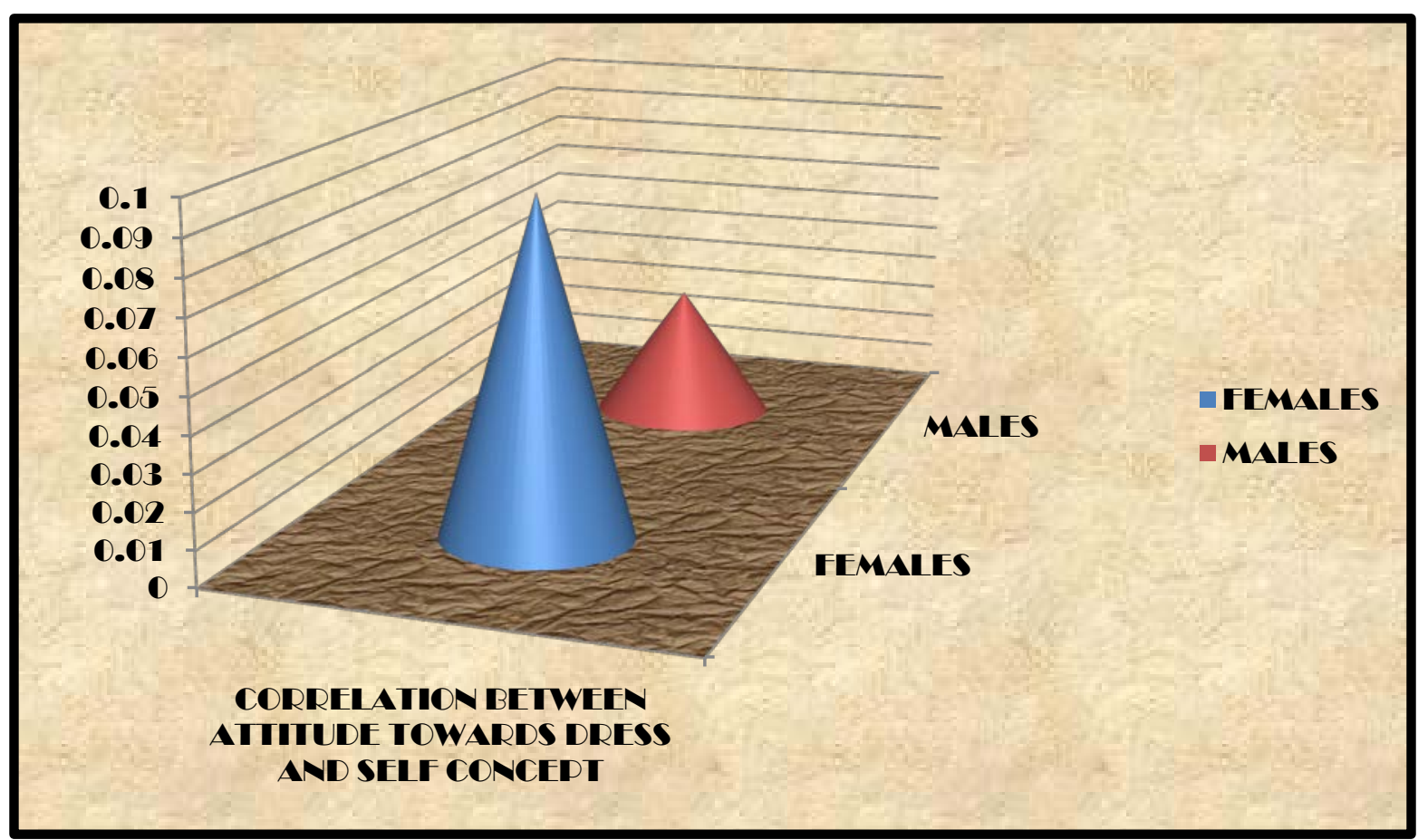

TABLE AND FIG 5 Shows the correlation of males and females between Attitude towards dress and Self Concept. The correlation is a slight positive, almost negligible one in either case but it is seen that it is slightly higher in girls than boys. Thus more favourable the attitude towards dress the better the self concept.

TABLE 6. Table showing Correlations of Attitude towards dress and various aspects of self concept taken individually.

\begin{tabular}{|l|l|l|}
\hline DESCRIPTION & FEMALES & MALES \\
\hline $\begin{array}{l}\text { Correlation Between Attitude Towards Dress And ‘Aesthetic’ } \\
\text { Aspect Of Self Concept }\end{array}$ & $\mathbf{- 0 . 2 2}$ \\
\hline $\begin{array}{l}\text { Correlation Between Attitude Towards Dress And 'Character' } \\
\text { Aspect Of Self Concept }\end{array}$ & $\mathbf{0 . 2 3}$ & $\mathbf{. 0 9}$ \\
\hline $\begin{array}{l}\text { Correlation Between Attitude Towards Dress And 'Social’ } \\
\text { Aspect Of Self Concept }\end{array}$ & $\mathbf{. 0 0 7}$ & $\mathbf{. 0 6 9}$ \\
\hline $\begin{array}{l}\text { Correlation Between Attitude Towards Dress And ‘Emotional’ } \\
\text { Aspect Of Self Concept A07 }\end{array}$ & $\mathbf{- 0 . 2 2}$ \\
\hline $\begin{array}{l}\text { Correlation Between Attitude Towards Dress And } \\
\text { 'Intellectual' Aspect Of Self Concept }\end{array}$ & $\mathbf{- 0 . 0 0 2 1}$ \\
\hline
\end{tabular}

\section{DISCUSSION}

\section{Comparison between female and male students based on their attitude towards dress-}

As far as Attitude towards Dress is concerned there is not much of a difference between females and males seen in the data collected. The mean attitude score of females is $\mathbf{9 7 . 0 7}$ and that of males is $\mathbf{9 5 . 5 4}$, thus a difference of $\mathbf{1 . 5 3}$ unit. The difference is small enough and girls

(C) The International Journal of Indian Psychology, ISSN 2348-5396 (e)| ISSN: 2349-3429 (p) | 35 


\section{A Comparative Study of the Relationship of Attitude towards Dress and Self-Concept between Female and Male Students of College}

have very slightly more favourable attitude towards dress than boys. Probably the girls harp upon the importance of dressing up more than boys. Here dress not only includes the clothes we wear but also how we wear them, how we carry them, bodily modifications (dieting, exercising etc), body supplements (make up, lotions etc), fragrances, dressing style and the like.

Moreover this slight a difference has occurred by chance and is not significant as the probability of significance obtained through $\mathbf{t}$ - test is $\mathbf{. 3 7}$ which is not significant. (neither at .05 nor at .01 level)

The highest score obtained among girls is 113 by Sanya Kumar and Ayushi whereas the highest score obtained by boys is 110 by Aman. As far as category is concerned both girls and boys fall in the "favourable attitude towards dress", neither do fall in highly favourable, neutral or unfavourable categories. This is quite obvious due to the age group they belong to. Young college students are anticipated to have favourable attitude towards dress. Since the students are exposed to similar academic milieu it was indeed anticipated that they would not differ significantly from one another. A comparison between professional and government university can be further investigated.

\section{Comparison between female and male students on the basis of self concept scores}

As far as mean self-concept scores are concerned the females have a score of $\mathbf{4 8 8 . 4 7}$ and males have a score of $\mathbf{4 6 5 . 4 6}$, a difference of $\mathbf{2 3 . 0 2}$ units. The difference is larger enough than in attitude towards dress thus the girls seem to have a much higher self concept than boys. Here the self concept measured the perceived self that is what do students think of themselves and not necessarily who they really are, what they want to be or what they think others think of them but it pertains to what they are in their own eyes. Thus girls have a more positive self concept about themselves than boys. Having a more positive self-concept means looking at oneself more positively and favourably, evaluating oneself more positively.

The highest score on self concept among girls is 587 (Manisha Arora) whereas in boys it is 574 (Suhans). It is interesting to note that Manisha who scored highest on self concept also has a high score on attitude towards dress. Thus it seems that the one giving importance to dress (what and how one wears) tends to have higher self concept. But on the contrary it is also seen among boys that Krishn Mohan who scored highest on attitude towards dress scored second lowest on self concept. Therefore it seems to be an opposite case for males, having a favourable attitude towards the importance of dress does not necessarily make them high on self evaluations thus as far as the boys are concerned factors other than dress, looks, and the like play importance in influencing their self concept.

The difference between boys and girls is a significant one, and has not occurred by chance. The probability through $\mathbf{T}$ test is $\mathbf{. 0 5}$, thus significant at .05 level but not .01 level. 


\section{A Comparative Study of the Relationship of Attitude towards Dress and Self-Concept between Female and Male Students of College}

Thus with 95\% surety it can be said that the difference between boys and girls on self concept scores has not occurred by chance and is significant.

Comparison between college going female and male students on the basis of correlation between attitude towards dress and self concept On the basis of correlation between total scores of attitude towards dress and self concept. As far as the correlations between the total scores of attitude towards dress and self concept are concerned the correlation between the two variables for girls is $\mathbf{. 0 9 3}$ and for boys is .037 The correlation is a slight positive, almost negligible one in either case but it is seen that it is slightly higher in girls than boys. Thus only to some extent more favourable the attitude towards dress the better the self concept. (or vice versa, the better the self-concept the more favourable the attitude towards dress). Therefore majorly it seems that attitude towards dress is not closely linked with self concept, thus self concept is influenced more by other variables rather than the external appearance. The intrinsic talents, skills, abilities and the like could be more important in this respect rather than external looks. But this area needs further exploration to convince us thus. The girl with the highest score on attitude towards dress scores 456 on self concept whereas the female who scores lowest on the attitude towards dress scores 506 on self concept, higher than 456. Thus it is not necessary that higher the attitude, the higher will be the self concept.

\section{On the basis of correlation between attitude towards dress and aesthetic self concept-}

The correlation between attitude towards dress and aesthetic aspect of self concept is (-.22 ) negative low correlation, definite but small relationship in girls, thus implying that more favourable the attitude towards dress among girls lesser the aesthetic self concept and vice versa. The correlation between attitude towards dress and aesthetic aspect of self concept in boys (.27) is positive low correlation, definite but small relationship, thus implying more favourable the attitude the higher the aesthetic self concept of males and vice versa. This demonstrates an important difference between males and females. In girls it is seen that probably when their aesthetic self concept is lower they give more importance to outward appearance and attire. Though the correlation is small but it is negative. Probably when they don't see themselves favourably on an aesthetic level they give more importance to outer appearance and clothes and when they see themselves favourably on aesthetic level they don't give importance to clothes.(eg. if I consider myself pretty, graceful, attractive I would feel I'll look good in whatever I wear and I don't need much external modifications, but one who sees herself lowly on aesthetic level would believe in making outward changes, like make up to cover up distortions, excessive dieting, etc.)

Some adjectives on aesthetic self concept includes graceful, attractive, artistic and the like. Thus if females find themselves graceful, attractive and the like they don't act, feel or believe that clothes, outside looks are important to look, feel or do good in various fields in life. Whereas it's the polar opposite for males, the correlation is positive thus implying that higher their aesthetic self concept, more favourable their attitude towards dress. Probably for 


\section{A Comparative Study of the Relationship of Attitude towards Dress and Self-Concept between Female and Male Students of College}

college going males ones clothes, external appearance are linked with being attractive and the like. Thus it can be said that if boys see themselves favourably on the aesthetic level, they act, feel, believe positively about the importance of attire. Thus probably if they have a high aesthetic self concept they are more conscious about what they wear and how they look whereas in college going females it is the opposite, the higher the aesthetic self concept the lesser are they conscious about what and they wear. Whereas it's not the same for boys. (eg. an attractive, well built boy is also found to be well dressed whereas who sees himself lowly on aesthetic self doesn't bother to take care of external looks)

\section{On the basis of correlation between attitude towards dress and character self concept-}

The correlation between attitude towards dress and character aspect of self concept (.23) is positive, low correlation, definite but small relationship in females, thus implying that more the favourable attitude is towards dress higher the character aspect of self concept. The correlation between attitude towards dress and character aspect of self concept (.o9) is slight almost negligible in boys. Thus hardly any relationship between attitude towards dress and character aspect of self concept in males. Thus the variable of dress is related to ones character more for girls than boys. This could be the result of difference in socialization of girls and boys. For girls character is positively related to dress. What one wears, how she wears etc influences her mental moral strength.

\section{On the basis of correlation between attitude towards dress and social self concept-}

Correlation between attitude towards dress and social aspect of self concept (.007) is slight positive, almost negligible in female students, thus implying that there is no significant relationship between attitude towards dress and social aspect of self concept in females. But the slight relationship is positive, thus implying that one sees oneself favourably socially if he believes in the importance of outer appearance and dress. Correlation between attitude towards dress and social aspect of self concept in males (.069) is also slight positive, almost negligible, thus implying that there is no significant relationship between attitude towards dress and social aspect of self concept in males. But the slight relationship is positive, thus implying that one sees oneself favourably socially if he believes in the importance of outer appearance and dress.

\section{On the basis of correlation between attitude towards dress and emotional self concept-}

Clearly and interestingly the correlation between attitude towards dress and Emotional aspect of self concept is (.007) slight positive, almost negligible relationship in girls whereas it is (-.22) negative, low correlation, definite but small relationship in boys. This is very interesting to note that boys firstly, have a higher correlation as compared to girls. Secondly, have a negative correlation as compared to girls. Thus stronger the emotional self concept less favourable the attitude towards dress in boys. Thus it seems that if boys see themselves as emotionally more stable they are less concerned about outer appearance. Whereas there is hardly any relationship between these two variables in girls and the slight relationship is also 


\section{A Comparative Study of the Relationship of Attitude towards Dress and Self-Concept between Female and Male Students of College}

positive. Thus ones belief in importance of dress isn't an important variable in determining ones emotional state.

\section{On the basis of correlation between attitude towards dress and intellectual self concept-}

Correlation between attitude towards dress and Intellectual aspect of self concept is (-.0021) slight negative, almost negligible in girls, whereas it is (.102) slight positive, almost negligible in boys, thus implying that although the relationship between attitude towards dress and Intellectual aspect of self concept among boys and girls is not very significant but in boys it is positive whereas in girls it is negative. This means that stronger the intellectual self concept of girls less favourable the attitude towards dress. Thus implying if girls are see themselves as more intelligent, critical, analytical, alert etc they don't believe very strongly in the importance of outer appearances than girls who feel they are less intelligent, alert, analytical.

\section{CONCLUSION}

The results obtained after analysing the data show that there is no significant difference between mean attitude towards dress scores of boys and girls hence the null hypothesis Ho1 is accepted and There is a significant difference between mean self-concept scores of boys and girls. (It is significant at .05 level) thus the null hypothesis $\mathrm{Ho} 2$ is rejected. As well as one more hypothesis, There is no significant correlation between attitude towards dress and self concept. It is slight positive, almost negligible. Thus the null hypothesis Ho3 is partially rejected.

- $\quad$ There is a negative low correlation, definite but small relationship in girls, between attitude towards dress and aesthetic self concept. Thus the null hypothesis is rejected

- The correlation between Attitude towards Dress and aesthetic aspect of Self Concept in boys is positive low correlation, definite but small relationship. Thus the null hypothesis is rejected.

- $\quad$ The correlation between attitude towards dress and character aspect of self concept is positive, low correlation, definite but small relationship in females. thus the null hypothesis is rejected.

- $\quad$ The correlation between attitude towards dress and character aspect of self concept is slight almost negligible in boys. The null hypothesis is partially rejected

- $\quad$ The correlation between attitude towards dress and social self concept is slight positive, almost negligible in female students, thus the null hypothesis is partially rejected.

- $\quad$ Correlation between attitude towards dress and social aspect of self concept in males is also slight positive, almost negligible, thus the null hypothesis is partially rejected.

- The correlation between attitude towards dress and Emotional aspect of self concept is slight positive, almost negligible relationship in girls, thus the null hypothesis is partially rejected.

- Whereas it is negative, low correlation, definite but small relationship in boys. Thus the null hypothesis is rejected. 


\section{A Comparative Study of the Relationship of Attitude towards Dress and Self-Concept between Female and Male Students of College}

- $\quad$ Correlation between attitude towards dress and Intellectual aspect of self concept is slight negative, almost negligible in girls, whereas it is slight positive, almost negligible in boys, thus null hypothesis is partially rejected.

\section{Acknowledgments}

The author appreciates all those who participated in the study and helped to facilitate the research process.

\section{REFERENCES}

Baumeister, R. F. (Ed.) (1999). The self in social psychology. Philadelphia, PA: Psychology Press (Taylor \& Francis).

Baumgartner, Jenifer. You Are What You Wear. Da Capo Lifelong Books. (March 2012)

Bee, H. L. (1992). The developing child. London: HarperCollins.

Ben C. Fletcher D.Phil., Oxon. What your clothes might be saying about you. Psychology Today.

Boundless. “Attitudes.” Boundless Psychology. Boundless, 20 Sep. 2016. Retrieved 30 Nov. 2016 from https://www.boundless.com/psychology/textbooks/boundless-psychologytextbook/social-psychology-20/social-cognition-103/attitudes-391-12926/ Coopersmith, S. (1967). The antecedents of self-esteem. San Francisco: Freeman.

"Exploring the Latent Structure of Strength-Related Attitude Attributes". Advances in Experimental Social Psychology. 1-67.

Kuhn, M. H. (1960). Self-attitudes by age, sex and professional training. Sociological Quarterly, 1, 39-56.

Lewis, M. (1990). Self-knowledge and social development in early life. In L. A. Pervin (Ed.), Handbook of personality (pp. 277-300). New York: Guilford.

Miller, D. T., \& Ross, M. (1975). Self-serving biases in the attribution of causality: Fact or fiction? Psychological Bulletin, 82, 213-225

Morse, S. J. \& Gergen, K. J. (1970). Social comparison, self-consistency and the concept of self. Journal of Personality and Social Psychology, 16, 148-156.

Rogers, C. (1959). A theory of therapy, personality and interpersonal relationships as developed in the client-centered framework. In (ed.) S. Koch, Psychology: A study of a science. Vol. 3: Formulations of the person and the social context. New York: McGraw Hill.

Van Bavel, J.; Xiao, Y.J.; Cunningham, W.A. (2012). "Evaluation is a dynamic process: Moving beyond dual systems models". Social and Personality Psychology Compass. 6(6): 438-454.

Zajonc, R. B. (1968). "Mr.". Journal of Personality and Social Psychology Monograph Supplement. 1-27

How to cite this article: Ahuja $H$ (2017). A Comparative Study of the Relationship of Attitude towards Dress and Self-Concept between Female and Male Students of College. International Journal of Indian Psychology, Vol. 5, (1), DIP: 18.01.064/20170501, DOI: $10.25215 / 0501.064$

(C) The International Journal of Indian Psychology, ISSN 2348-5396 (e)| ISSN: 2349-3429 (p) | 40 